\title{
Associations between the lipid profile and the lumbar spine bone mineral density and trabecular bone score in elderly Iranian individuals participating in the Bushehr Elderly Health Program: a population-based study
}

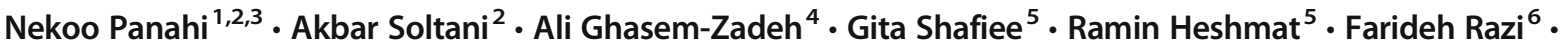 \\ Neda Mehrdad ${ }^{7} \cdot$ Iraj Nabipour $^{8} \cdot$ Bagher Larijani $^{3} \cdot$ Afshin Ostovar $^{1}$
}

Received: 26 July 2018 / Accepted: 24 April 2019/Published online: 11 May 2019

(C) International Osteoporosis Foundation and National Osteoporosis Foundation 2019

\begin{abstract}
Summary We hypothesized that the lipid profile or dyslipidemia may have an influence on the bone mineral density and bone microstructure in an elderly Iranian population. The results of this study showed some significant associations between the serum lipid levels and the lumbar spine and femoral areal bone mineral densities and the trabecular bone score (TBS).

Purpose Serum lipid abnormalities are possible risk factors for cardiovascular diseases and osteoporosis. Our aim was to evaluate the associations between the lipid profile and the areal bone mineral density (aBMD) and trabecular bone score in an elderly Iranian population.

Methods The study subjects included 2426 elderly women and men participating in the second stage of the Bushehr Elderly Health program, a population-based prospective cohort study. The aBMDs of the lumbar spine and femoral neck and the lumbar spine texture were measured using dual-energy X-ray absorptiometry and the TBS algorithm, respectively. The associations between the lipid profiles and the aBMDs and TBSs were examined using multivariable linear regression analyses stratified by sex and adjusted for potential confounders.

Results In men, we found negative correlations between the lumbar spine aBMD and TBS and the total cholesterol (TC), highdensity lipoprotein cholesterol (HDL-C), and low-density lipoprotein cholesterol (LDL-C) levels (TC: $p<0.001$ and $p<0.006$, HDL-C: $p=0.002$ and $p=0.004$, and LDL-C: $p<0.001$ and $p<0.009$, respectively). However, only the HDL-C level was negatively associated with the aBMD in women $(p=0.016)$. A positive and statistically significant correlation was found between the serum triglyceride (TG) level and the aBMD in the women $(p<0.001)$. The TG level and the TBS were not statistically significantly correlated in either sex, and the TBS was not correlated with any of the lipid values in women.

Conclusion The results of this study showed some significant but generally weak associations between the lipid profile and the aBMD. The associations that were significant for both the men and the women included positive associations between the TG level and the femoral neck aBMD, as well as the HDL-C level and the femoral neck and lumbar spine aBMDs.
\end{abstract}

Afshin Ostovar

aostovar@tums.ac.ir

1 Osteoporosis Research Center, Endocrinology and Metabolism Clinical Sciences Institute, Tehran University of Medical Sciences, Tehran, Iran

2 Evidence Based Medicine Research Center, Endocrinology and Metabolism Clinical Sciences Institute, Tehran University of Medical Sciences, Tehran, Iran

3 Endocrinology and Metabolism Research Center, Endocrinology and Metabolism Clinical Sciences Institute, Tehran University of Medical Sciences, Tehran, Iran

4 Departments of Medicine and Endocrinology, University of Melbourne, Australia, Melbourne, Australia
5 Chronic Diseases Research Center, Endocrinology and Metabolism Population Sciences Institute, Tehran University of Medical Sciences, Tehran, Iran

6 Diabetes Research Center, Endocrinology and Metabolism Clinical Sciences Institute, Tehran University of Medical Sciences, Tehran, Iran

7 Elderly Health Research Center, Endocrinology and Metabolism Population Sciences Institute, Tehran University of Medical Sciences, Tehran, Iran

8 The Persian Gulf Marine Biotechnology Research Center, The Persian Gulf Biomedical Sciences Research Institute, Bushehr University of Medical Sciences, Bushehr, Iran 
Keywords Bone $\cdot$ Bone mineral density $\cdot$ Elderly $\cdot$ Iran $\cdot$ Lipid $\cdot$ Trabecular bone score

\section{Introduction}

As the population ages, we are faced with many more agerelated degenerative diseases than ever before, including osteoporosis. Although osteoporosis is more common in postmenopausal women, many elderly men suffer from this condition as well, and they are often left undiagnosed and untreated [1]. Osteoporosis-induced fractures and complications impose great short-term and long-term burdens [2]. The prevalences of osteoporosis and low bone mass in Iran have been reported to be as high as $19 \%$ and $40 \%$, respectively, for women and $12 \%$ and $33 \%$, respectively, for men, according to one meta-analysis study [3].

Osteoporosis and cardiovascular disease are two major public health problems, especially among the elderly, and they are strongly linked according to previous epidemiological studies $[4,5]$. One systematic review revealed that individuals with subclinical cardiovascular disease are 2.3 to 3.0 times more prone to bone loss and fragility fractures when compared with individuals without this condition. It also showed that those individuals with low bone mass are more prone to cardiovascular events and that they have higher mortality rates [6]. Moreover, cardiovascular diseases and osteoporosis share certain risk factors, such as age, premature menopause, genetics, a sedentary lifestyle, smoking, a vitamin D deficiency, and diabetes; however, other factors, such as gender and obesity, can have different effects upon these two conditions [7, 8]. Some pathophysiological explanations and common genetic backgrounds could contribute to these associations, including those biological factors contributing to vascular atherosclerosis and bone remodeling, such as oxidized lipids, sclerostin, osteoprotegerin, and fibroblast growth factor-23 [7, 9-12]. The estrogen deficiency and inflammatory cytokines exhibited during the postmenopausal period can affect osteoclast activity, which can lead to bone loss; however, they also seem to be associated with atherogenesis $[13,14]$. Conversely, the medications used for the treatment of osteoporosis and dyslipidemia, such as bisphosphonates and statins, seem to affect both bone tissue and atherosclerotic plaques $[15,16]$. A population-based study in Spain revealed a higher femoral neck bone mineral density (BMD) in women taking lipophilic statins; however, different trends have been observed among different sexes and different types of statins [17].

Dyslipidemia is a major risk factor for cardiovascular disease, and some studies have suggested that it is associated with a low bone mass, but there is great inconsistency among the reported findings $[4,7,18-25]$.

Although the areal BMD (aBMD) is considered for the diagnosis of osteoporosis, most fragility fractures occur in osteopenic or normal bone. Other bone features that determine the bone quality, such as the microarchitecture, mineralization level, bone remodeling rate, and microdamage accumulation, also contribute to fragility fractures. The trabecular bone score (TBS) was derived from lumbar spine dual-energy X-ray absorptiometry (DXA) images measured using TBS iNsight software (version 2.2; Medimaps Group, Plan-les-Ouates, Switzerland). It was developed to assess the image texture as a novel index for the lumbar spine trabecular microstructure state, and it was introduced as a complement to the aBMD and partially independent from the aBMD for assessing the fracture risk [26-28]. The TBS change predictors differ from those of the aBMD in elderly men; for example, weight loss is associated with a decreased aBMD, while weight gain and obesity are associated with a decreased TBS [29].

Most previous studies about the relationships between the lipid parameters and the aBMD have been performed using smaller samples, and they focused mainly on postmenopausal women with regard to a few confounding factors. Therefore, the aim of this study was to evaluate whether higher lipid levels are associated with a lower aBMD and a lower TBS in an elderly Iranian population. To the best of our knowledge, this is the first study to examine the correlations between the lipid profile and the TBS and aBMD in a large-scale population of elderly women and men while considering several potential confounders.

\section{Methods}

\section{Subjects}

The present study included 1260 women and 1166 men older than 60 years (age means of $69.16( \pm 6.35)$ years old and $69.54( \pm 6.44)$ years old, respectively) participating in the second stage of the Bushehr Elderly Health (BEH) program. The rationale and design of the original study has been described elsewhere [30, 31]. In summary, the $\mathrm{BEH}$ program is a population-based prospective cohort study that has been conducted in Bushehr, a southern province of Iran, since March of 2013. The main aim of this study was to investigate the prevalence of noncommunicable diseases and the associated risk factors. The inclusion criteria were an age $\geq 60$ years old and adequate physical and mental abilities to participate in the evaluation program. In the second stage, which began in October of 2015 , the study was designed to estimate the prevalences of musculoskeletal disorders, including osteoporosis (among other non-communicable diseases) and their risk factors and the outcomes of these disorders, such as falling, fractures, poor mobility, and functional 
Table 1 Descriptive characteristics of the study population

\begin{tabular}{|c|c|c|c|}
\hline & & Women $(n=1260)$ & $\operatorname{Men}(n=1166)$ \\
\hline Age (years) & & $69.2(6.4)$ & $69.5(6.4)$ \\
\hline \multirow[t]{6}{*}{ Body characteristics } & Weight $(\mathrm{Kg}) *$ & $66.6(13.1)$ & $72.3(12.4)$ \\
\hline & Height $(\mathrm{cm})^{*}$ & $152.2(6.1)$ & $165.9(6.3)$ \\
\hline & BMI $\left(\mathrm{Kg} / \mathrm{cm}^{2}\right)^{*}$ & $28.7(5.3)$ & $26.2(4.0)$ \\
\hline & Waist circumference $(\mathrm{cm})^{*}$ & $100.2(12.5)$ & $97.1(11.2)$ \\
\hline & Hip circumference $(\mathrm{cm})^{*}$ & $105.6(11.2)$ & $99.3(7.7)$ \\
\hline & Years since menopause & $21.3(7.9)$ & - \\
\hline \multirow[t]{6}{*}{ Lipid profile } & $\mathrm{TG}(\mathrm{mg} / \mathrm{dl})^{*}$ & $141.2(72.0)$ & $130.3(68.3)$ \\
\hline & $\mathrm{TC}(\mathrm{mg} / \mathrm{dl})^{*}$ & $190.4(45.5)$ & $173.3(40.8)$ \\
\hline & HDL-C (mg/dl)* & $48.6(11.5)$ & $43.1(10.1)$ \\
\hline & LDL-C (mg/dl)* & $113.9(39.7)$ & $104.6(34.8)$ \\
\hline & LDL-C to HDL-C ratio & $2.5(1.0)$ & $2.5(0.9)$ \\
\hline & TC to HDL-C ratio & $4.1(1.3)$ & $4.2(1.2)$ \\
\hline \multirow[t]{7}{*}{ Bone status* } & TBS (L1-L4) & $1.241(0.088)$ & $1.354(0.092)$ \\
\hline & Lumbar spine aBMD $\left(\mathrm{g} / \mathrm{cm}^{2}\right)$ & $0.811(0.143)$ & $0.990(0.172)$ \\
\hline & Femoral neck aBMD $\left(\mathrm{g} / \mathrm{cm}^{2}\right)$ & $0.588(0.111)$ & $0.731(0.1340$ \\
\hline & Total hip aBMD $\left(\mathrm{g} / \mathrm{cm}^{2}\right)$ & $0.756(0.128)$ & $0.944(0.143)$ \\
\hline & Osteoporosis ( $T$ score -2.5 or less) & $524(44.6 \%)$ & $176(16.1 \%)$ \\
\hline & Osteopenia ( $T$ score between -1 and -2.5$)$ & $522(44.4 \%)$ & $458(42.0 \%)$ \\
\hline & Normal ( $T$ score -1 or more $)$ & $129(11.0 \%)$ & $457(41.9 \%)$ \\
\hline \multirow[t]{3}{*}{ Biochemistry } & Calcium* (mg/dl) & $9.38(0.52)$ & $9.30(0.51)$ \\
\hline & Phosphorus* (mg/dl) & $4.17(0.51)$ & $3.88(0.56)$ \\
\hline & Alkaline phosphatase* (IU/L) & $231.87(78.11)$ & $208.22(71.23)$ \\
\hline \multirow[t]{5}{*}{ Education level* } & University & $29(2.31 \%)$ & $164(14.07 \%)$ \\
\hline & High school & $111(8.82 \%)$ & $249(21.36 \%)$ \\
\hline & Secondary school & $135(10.73 \%)$ & $223(19.13 \%)$ \\
\hline & Primary school & $396(31.48 \%)$ & $316(27.10 \%)$ \\
\hline & No education & $587(46.66 \%)$ & $214(18.35 \%)$ \\
\hline Smoking (yes)* & & $176(14.1 \%)$ & $242(20.8)$ \\
\hline Physical activity (yes) & & $287(23.0 \%)$ & $280(24.3 \%)$ \\
\hline
\end{tabular}

Data are presented as Mean (SD) for continuous variables and number (percent) for categorical variables. $T G$, triglyceride; $T C$, total cholesterol; $H D L$ - $C$, high-density lipoprotein cholesterol; $L D L$ - $C$, low-density lipoprotein cholesterol; $a B M D$, areal bone mineral density; TBS, trabecular bone score; ${ }^{*} p$ value $<0.001$ dependence, during the follow-ups among the elderly participants. The data collection was designed to occur at 2.5-year intervals.

\section{aBMD and trabecular structure measurements}

All of the subjects underwent lumber spine (L1-L4) and proximal hip aBMD measurements using DXA (Discovery Wi Bone Densitometer; Hologic, Bedford, MA, USA), following the International Society for Clinical Densitometry guidelines [32]. We used TBS iNsight software, which indirectly measures the lumbar spine trabecular microstructure based on a textural analysis of the DXA images of the lumbar spine region [33, 34].

\section{Lipid profile measurements}

The lipid profile, including the total cholesterol (TC), triglyceride (TG), low-density lipoprotein cholesterol (LDL-C), and high-density lipoprotein cholesterol (HDL-C) levels, was measured using the enzymatic photometric method with a commercial kit (Pars Azmun Co., Karaj, Iran) with total precision errors (expressed as the coefficient of variation) of $1.6 \%, 1.9 \%, 1.5 \%$, and $1.8 \%$, respectively.

\section{Statistical analysis}

We described the data using frequencies and percentages for the categorical variables and means ( \pm standard deviations) for the continuous variables. Where applicable, we used the two- 

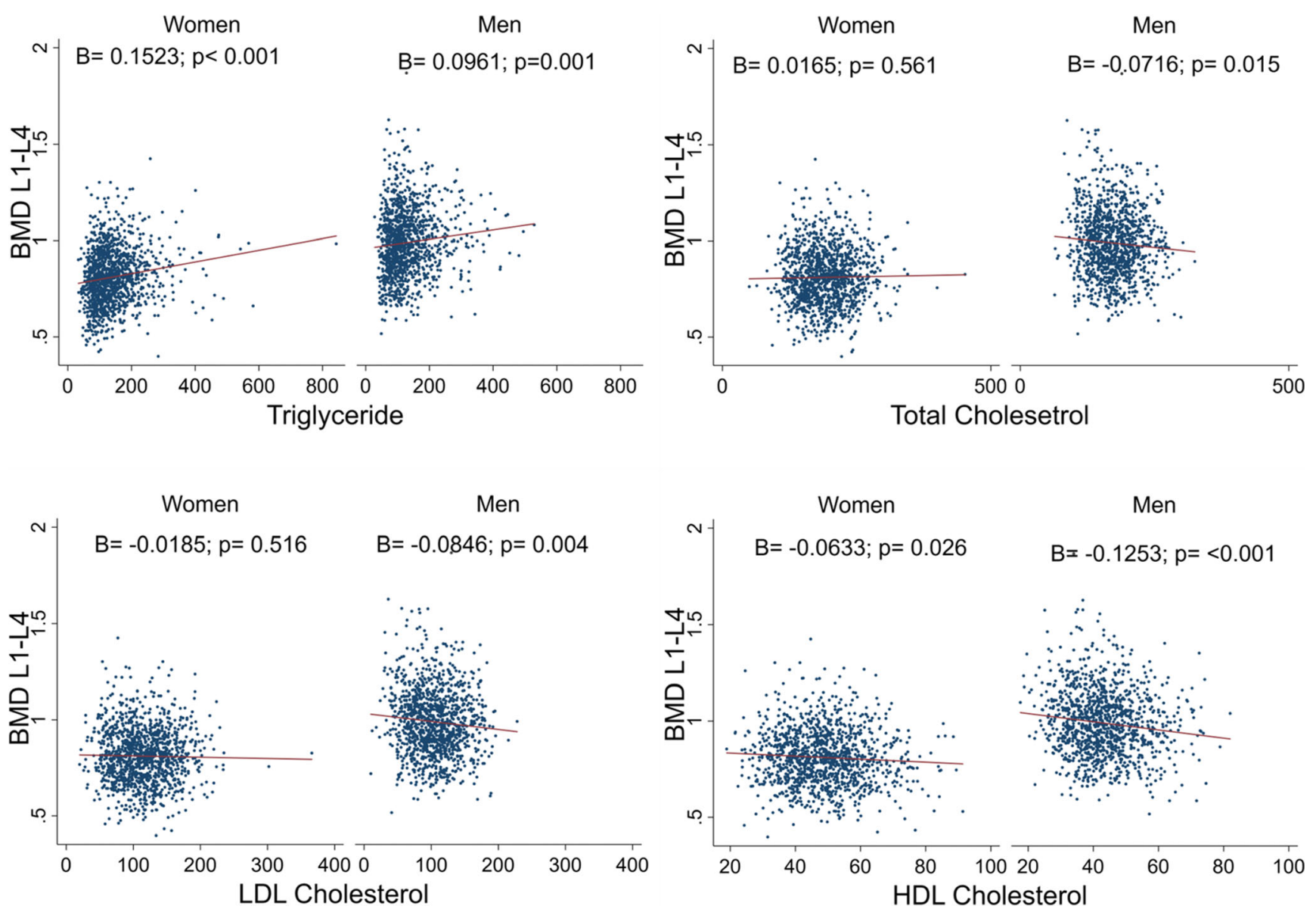

Fig. 1 Scatter plots and least-square fitted lines of lipid profile and lumbar spine areal bone mineral density; B: Standardized beta.

group independent $t$ test for the continuous variables and the Pearson chi-squared test for the categorical variables in order to compare the variables between the women and the men. We examined the associations between the lipid profiles and the aBMD and TBS of the lumbar spine (L1-L4) and the femoral neck aBMD using univariable and multivariable linear regression analyses. We stratified the participants by sex, and we adjusted the analysis for the other potential confounders. The models used for the regression analysis included the unadjusted values, the reduced model adjusted for the main confounders (age, body mass index (BMI), educational level, and smoking status), and the full model adjusted for the other potential confounders (waist circumference, years since menopause (for the women), physical activity, calcium, phosphorus, and alkaline phosphatase). We also calculated partial etasquared values as a measure of the effect size.

We divided the participants according to the tertiles of the TBS and the lumbar spine and femoral neck aBMDs, and we considered the new variable to be our outcome (three levels). Due to the multinomial categorized types of TBSs and aBMDs, we used a multinomial logistic regression (the participants in the first tertile were considered to be the reference group). For the continuous variables in this model, we had the relative risk ratio (RRR) for a one-unit increase in the continuous variable being equal to the exponentiation (beta). We selected each variable to include in the model as a potential confounder if the corresponding $p$ value was less than 0.2 in the univariate analysis. Those $p$ values of less than 0.05 were considered to be statistically significant.

The statistical analysis was performed using 2013 Stata Statistical Software (Release 13; StataCorp LLC, College Station, TX, USA).

\section{Results}

The basic characteristics of the participants, including the age, body composition, educational level, bone status, and lipid profile, are presented in Table 1.

The men had statistically significantly lower BMI, TG, TC, HDL-C, and LDL-C levels when compared with the women $(p<0.001)$. However, the LDL-C to HDL-C ratio and the cholesterol to HDL-C ratio tended to be higher in the men, but not statistically significantly $(p=0.065$ and $p=0.082$, respectively). 

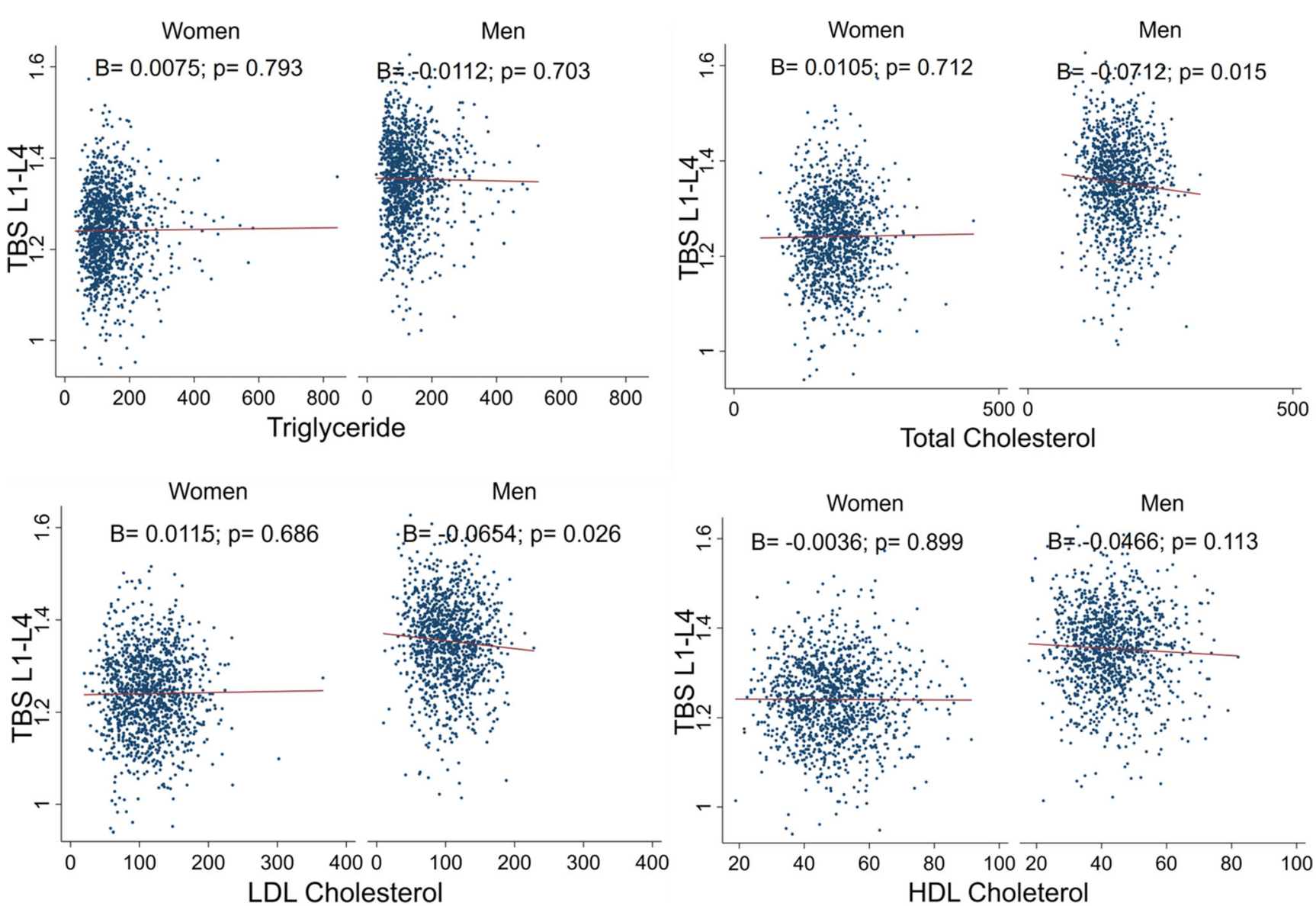

Fig. 2 Scatter plots and least-square fitted lines of lipid profile and trabecular bone score; B: Standardized beta.

The mean lumbar aBMD was lower in the women when compared with the men $\left(0.823( \pm 0.149) \mathrm{g} / \mathrm{cm}^{2}\right.$ vs. $1.010( \pm$ $\left.0.180) \mathrm{g} / \mathrm{cm}^{2}, p<0.001\right)$. We found similar trends for the femoral neck and total hip aBMDs as well as the TBS (Table 1).

The associations between the lipid profile and the lumbar spine aBMD and TBS are illustrated in Figs. 1 and 2. The results of the unadjusted linear regression, the results after adjusting for the age, BMI, educational level, and smoking status in the reduced model, and the results after adjusting for the age, BMI, waist circumference, years since menopause (for the women), physical activity, educational level, smoking status, calcium, phosphorus, and alkaline phosphatase in the full model, stratified by sex, are presented in Table 2 . The etasquared values are presented as measures of the effect size as well.

In the men, we found negative correlations between the lumbar spine aBMD and the TBS but not the femoral neck aBMD and the TC level in the full model $(\beta=-0.0996$ and $p<0.001, \beta=-0.0784$ and $p=0.006$, and $\beta=-0.0477$ and $p=0.087$, respectively). The lumbar spine aBMD, TBS, and femoral neck aBMD were all inversely correlated with the HDL-C and LDL-C values in the men (HDL-C: $\beta=-$ 0.0892 and $p=0.002, \beta=-0.0832$ and $p=0.004$, and $\beta=-$
0.0644 and $p=0.021$, respectively; LDL-C: $\beta=-0.0987$ and $p<0.001, \beta=-0.0742$ and $p=0.009$, and $\beta=-0.0644$ and $p=0.020$, respectively). However, the strengths of the associations, as indicated by the eta-squared, were generally weak and less than $1 \%$. In the men, the correlation between the lumbar spine aBMD and the TG level was not statistically significant after the adjustment in both models; however, the femoral neck aBMD was correlated with the TG level $(\beta=$ $0.0727, p=0.010$ ). No correlations were found between the TBS and the TG level in either the men or the women.

In the women, we found a negative correlation between the lumbar spine and the femoral neck aBMDs and the HDL-C level in the full model $(\beta=-0.0560, p=0.016$ and $\beta=-$ $0.0608, p=0.016$, respectively) with an eta-squared of less than $1 \%$. However, neither the lumbar spine and femoral neck aBMDs nor the TBS was statistically significantly correlated with the TC or the LDL-C values in the women (Table 2). However, the serum TG level had a positive and statistically significant correlations with the lumbar spine and femoral neck aBMDs in the women $(\beta=0.1050, p<0.001$ and $\beta=$ $0.0652, p=0.009$, respectively) with eta-squared values of $1.51 \%$ and $0.57 \%$, respectively. The TBS was not correlated with any of the lipids measured in the women. 
Table 3 Association between lipid profile and femoral neck aBMD

\begin{tabular}{|c|c|c|c|c|c|c|c|}
\hline \multirow[t]{3}{*}{ Lipids } & & \multicolumn{6}{|c|}{ Femoral neck aBMD tertiles } \\
\hline & & \multicolumn{3}{|c|}{ Women } & \multicolumn{3}{|c|}{ Men } \\
\hline & & $\mathrm{T} 1$ & $\mathrm{~T} 2$ & $\mathrm{~T} 3$ & $\mathrm{~T} 1$ & $\mathrm{~T} 2$ & $\mathrm{~T} 3$ \\
\hline \multirow[t]{3}{*}{ TG } & Model 1 & 1 & $\begin{array}{l}1.0018 \\
(0.9997,1.0039)\end{array}$ & $\begin{array}{l}1.0040 \\
(1.0019,1.0060)^{* *}\end{array}$ & 1 & $\begin{array}{l}1.0041 \\
(1.0018,1.0065)^{*}\end{array}$ & $\begin{array}{l}1.0056 \\
(1.0033,1.0080) * *\end{array}$ \\
\hline & Model 2 & 1 & $\begin{array}{l}1.0008 \\
(0.9987,1.0030)\end{array}$ & $\begin{array}{l}1.0030 \\
(1.0008,1.0052)^{*}\end{array}$ & 1 & $\begin{array}{l}1.0023 \\
(0.9999,1.0046)\end{array}$ & $\begin{array}{l}1.0031 \\
(1.0007,1.0055) *\end{array}$ \\
\hline & Model 3 & 1 & $\begin{array}{l}1.0011 \\
(0.9989,1.0033)\end{array}$ & $\begin{array}{l}1.0031 \\
(1.0008,1.0054)^{*}\end{array}$ & 1 & $\begin{array}{l}1.0022 \\
(0.9997,1.0046\end{array}$ & $\begin{array}{l}1.0030 \\
(1.0005,1.0054) *\end{array}$ \\
\hline \multirow[t]{3}{*}{$\mathrm{TC}$} & Model 1 & 1 & $\begin{array}{l}0.9994 \\
(0.9964,1.0024)\end{array}$ & $\begin{array}{l}1.0010 \\
(0.9980,1.0040)\end{array}$ & 1 & $\begin{array}{l}1.0014 \\
(0.9980,1.0049)\end{array}$ & $\begin{array}{l}0.9998 \\
(0.9963,1.0032)\end{array}$ \\
\hline & Model 2 & 1 & $\begin{array}{l}0.9994 \\
(0.9963,1.0026)\end{array}$ & $\begin{array}{l}1.0015 \\
(0.9981,1.0048)\end{array}$ & 1 & $\begin{array}{l}1.0005 \\
(0.9969,1.0040)\end{array}$ & $\begin{array}{l}0.9989 \\
(0.9952,1.0027)\end{array}$ \\
\hline & Model 3 & 1 & $\begin{array}{l}0.9996 \\
(0.9964,1.0029)\end{array}$ & $\begin{array}{l}1.0011 \\
(0.9976,1.0046)\end{array}$ & 1 & $\begin{array}{l}0.9997 \\
(0.9960,1.0034)\end{array}$ & $\begin{array}{l}0.9981 \\
(0.9942,1.0020)\end{array}$ \\
\hline \multirow[t]{3}{*}{ HDL-C } & Model 1 & 1 & $\begin{array}{l}0.9890 \\
(0.9775,1.0007)\end{array}$ & $\begin{array}{l}0.9808 \\
(0.9692,0.9926)^{*}\end{array}$ & 1 & $\begin{array}{l}0.9825 \\
(0.9689,0.9963)^{*}\end{array}$ & $\begin{array}{l}0.9821 \\
(0.9685,0.9960)^{*}\end{array}$ \\
\hline & Model 2 & 1 & $\begin{array}{l}0.9884 \\
(0.9761,1.0009)\end{array}$ & $\begin{array}{l}0.9794 \\
(0.9662,0.9928)^{*}\end{array}$ & 1 & $\begin{array}{l}0.9890 \\
(0.9749,1.0030)\end{array}$ & $\begin{array}{l}0.9923 \\
(0.9772,1.0076)\end{array}$ \\
\hline & Model 3 & 1 & $\begin{array}{l}0.9870 \\
(0.9741,1.0001)\end{array}$ & $\begin{array}{l}0.9753 \\
(0.9613,0.9896)^{*}\end{array}$ & 1 & $\begin{array}{l}0.9901 \\
(0.9756,1.0048)\end{array}$ & $\begin{array}{l}0.9938 \\
(0.9783,1.0095)\end{array}$ \\
\hline \multirow[t]{3}{*}{ LDL-C } & Model 1 & 1 & $\begin{array}{l}0.9989 \\
(0.9955,1.0024)\end{array}$ & $\begin{array}{l}0.9999 \\
(0.9965,1.0033)\end{array}$ & 1 & $\begin{array}{l}1.0009 \\
(0.9968,1.0049)\end{array}$ & $\begin{array}{l}0.9973 \\
(0.9932,1.0014)\end{array}$ \\
\hline & Model 2 & 1 & $\begin{array}{l}0.9995 \\
(0.9958,1.0031)\end{array}$ & $\begin{array}{l}1.0009 \\
(0.9971,1.0048)\end{array}$ & 1 & $\begin{array}{l}1.0002 \\
(0.9960,1.0044)\end{array}$ & $\begin{array}{l}0.9970 \\
(0.9926,1.0015)\end{array}$ \\
\hline & Model 3 & 1 & $\begin{array}{l}0.9996 \\
(0.9959,1.0033)\end{array}$ & $\begin{array}{l}1.0006 \\
(0.9967,1.0046)\end{array}$ & 1 & $\begin{array}{l}0.9991 \\
(0.9948,1.0035)\end{array}$ & $\begin{array}{l}0.9959 \\
(0.9914,1.0004)\end{array}$ \\
\hline
\end{tabular}

Relative risk ratios with 95\% confidence intervals are presented. Model 1: unadjusted; Model 2: adjusted for age, BMI, education level, and smoking; Model 3: adjusted for age, BMI, waist circumference, years since menopause (for women), physical activity, education level, smoking, calcium, phosphorus, and alkaline phosphatase; $a B M D$, areal bone mineral density; $T G$, triglyceride; $T C$, total cholesterol; $H D L-C$, high-density lipoprotein cholesterol; $L D L-C$, low-density lipoprotein cholesterol. Femoral neck aBMD tertiles: for men: T1 less than 0.664 , T2 between 0.664 and $0.777, \mathrm{~T} 3$ more than 0.777 ; for women T1 less than 0.540 , T2 between 0.540 and 0.633 , T3 more than 0.633 ; $* p$ value $<0.05$, ** $p$ value $<0.001$

The LDL-C to HDL-C ratio was not statistically significantly correlated with the aBMDs or TBS in either sex. However, the TC to HDL-C ratio was statistically significantly correlated with the lumbar spine and femoral neck aBMDs in the women $(\beta=0.0553, p=0.023$ and $\beta=0.0632, p=$ 0.010 , respectively).

The associations between the tertiles of the aBMDs and TBS and the lipid profile are presented in Tables 3, 4, and 5 . After adjusting for the confounders, the men within the highest third of the lumbar aBMD had significantly lower TC, HDL-C, and LDL-C levels when compared with those within the lowest third $(\mathrm{RRR}=0.9941$ and $p=0.003$, RRR $=$ 0.9786 and $p=0.006$, and $\mathrm{RRR}=0.9926$ and $p=0.001$, respectively). The men within the third TBS tertile had statistically significantly lower TC and LDL-C levels $(\mathrm{RRR}=$ $0.9950, p=0.009$ and $\mathrm{RRR}=0.9939, p=0.006$, respectively). Moreover, the men in the third femoral neck aBMD tertile had a significantly higher TG levels when compared with those in the first tertile ( $R R R=1.0031, p=0.008)$.

However, the women within the highest tertiles of both the lumbar aBMD and femoral neck aBMD had significantly lower HDL-C levels $(\mathrm{RRR}=0.9812, p=0.012$ and $\mathrm{RRR}=$ 0.9753, $p=0.001$, respectively) and higher TG levels $(\mathrm{RRR}=1.0040, p=0.001$ and $\mathrm{RRR}=1.0031, p=0.008$, respectively) relative to those within the lowest third. The TBS tertiles were not associated with any of the measured lipids in the women (Table 5).

\section{Discussion}

In this study, we evaluated the associations between the aBMD and TBS (surrogates of the bone state) and the lipid profile in an elderly Iranian population, and we found some relationships (mainly in the men); however, an interpretation is difficult due to the many variables that can potentially affect the aBMD and TBS measurements.

Most studies about the correlations between the BMD and lipid profile are performed among women, especially postmenopausal women. Moreover, the different studies have conflicting results, and some of them are partially consistent with our findings. For example, some of the studies of Iranian [19] 
Table 2 Correlation between lipid profile and aBMD and TBS

\begin{tabular}{|c|c|c|c|c|c|c|c|c|c|c|c|c|c|}
\hline \multirow[t]{3}{*}{ Variables } & & \multicolumn{4}{|c|}{ Femoral neck aBMD } & \multicolumn{4}{|c|}{ Lumbar spine (L1-L4) aBMD } & \multicolumn{4}{|c|}{ Lumbar spine (L1-L4) TBS } \\
\hline & & \multicolumn{2}{|l|}{ Women } & \multicolumn{2}{|l|}{ Men } & \multicolumn{2}{|l|}{ Women } & \multicolumn{2}{|l|}{ Men } & \multicolumn{2}{|l|}{ Women } & \multicolumn{2}{|l|}{ Men } \\
\hline & & Beta & $\mathrm{Eta}^{2}$ & Beta & $\mathrm{Eta}^{2}$ & beta & $\mathrm{Eta}^{2}$ & beta & $\mathrm{Eta}^{2}$ & beta & $\mathrm{Eta}^{2}$ & beta & $\mathrm{Eta}^{2}$ \\
\hline \multirow[t]{3}{*}{ TG } & Model 1 & $0.1071 * *$ & & $0.1425 * *$ & & $0.1523 * *$ & & $0.0961 *$ & & 0.0075 & & -0.0112 & \\
\hline & Model 2 & $0.0625^{*}$ & $0.52 \%$ & $0.0737 *$ & $0.60 \%$ & $0.1039 * *$ & $1.49 \%$ & 0.0365 & $0.14 \%$ & 0.0243 & $0.07 \%$ & 0.0164 & $0.03 \%$ \\
\hline & Model 3 & $0.0652^{*}$ & $0.57 \%$ & $0.0727^{*}$ & $0.58 \%$ & $0.1050 * *$ & $1.51 \%$ & 0.0255 & $0.07 \%$ & 0.0406 & $0.19 \%$ & 0.0192 & $0.04 \%$ \\
\hline \multirow[t]{3}{*}{$\mathrm{TC}$} & Model 1 & 0.0118 & & -0.0210 & & 0.0165 & & $-0.0716^{*}$ & & 0.0105 & & $-0.0712 *$ & \\
\hline & Model 2 & 0.0207 & $0.06 \%$ & -0.0343 & $0.14 \%$ & 0.0158 & $0.03 \%$ & $-0.0863 *$ & $0.84 \%$ & 0.0176 & $0.04 \%$ & $-0.0657^{*}$ & $0.47 \%$ \\
\hline & Model 3 & 0.0201 & $0.06 \%$ & -0.0477 & $0.26 \%$ & 0.0160 & $0.03 \%$ & $-0.0996^{* *}$ & $1.10 \%$ & 0.0107 & $0.01 \%$ & $-0.0784^{*}$ & $0.67 \%$ \\
\hline \multirow[t]{3}{*}{ HDL-C (mg/dl) } & Model 1 & $-0.0714^{*}$ & & $-0.1073 * *$ & & $-0.0633 *$ & & $-0.1253^{* *}$ & & -0.0036 & & -0.0466 & \\
\hline & Model 2 & $-0.0553^{*}$ & $0.40 \%$ & $-0.0665^{*}$ & $0.50 \%$ & $-0.0552 *$ & $0.42 \%$ & $-0.0889^{*}$ & $0.87 \%$ & -0.0187 & $0.04 \%$ & $-0.0765^{*}$ & $0.63 \%$ \\
\hline & Model 3 & $-0.0608^{*}$ & $0.48 \%$ & $-0.0644 *$ & $0.47 \%$ & $-0.0560 *$ & $0.48 \%$ & $-0.0892 *$ & $0.88 \%$ & -0.0448 & $0.22 \%$ & $-0.0832 *$ & $0.75 \%$ \\
\hline \multirow[t]{3}{*}{ LDL-C (mg/dl) } & Model 1 & -0.0088 & & -0.0496 & & -0.0185 & & $-0.0846^{*}$ & & 0.0115 & & $-0.0654^{*}$ & \\
\hline & Model 2 & 0.0124 & $0.02 \%$ & -0.0494 & $0.28 \%$ & -0.0053 & $0.00 \%$ & $-0.0891 *$ & $0.90 \%$ & 0.0184 & $0.04 \%$ & $-0.0615^{*}$ & $0.41 \%$ \\
\hline & Model 3 & 0.0114 & $0.02 \%$ & $-0.0644 *$ & $0.48 \%$ & -0.0047 & $0.00 \%$ & $-0.0987 * *$ & $1.09 \%$ & 0.0112 & $0.01 \%$ & $-0.0742 *$ & $0.60 \%$ \\
\hline \multirow{3}{*}{$\begin{array}{l}\text { LDL-C to } \\
\text { HDL-C ratio }\end{array}$} & Model 1 & 0.0349 & & 0.0185 & & 0.0114 & & 0.0026 & & 0.0108 & & -0.0241 & \\
\hline & Model 2 & 0.0461 & $0.28 \%$ & 0.0000 & $0.00 \%$ & 0.0226 & $0.07 \%$ & -0.0214 & $0.05 \%$ & 0.0239 & $0.07 \%$ & -0.0038 & $0.00 \%$ \\
\hline & Model 3 & 0.0451 & $0.28 \%$ & -0.0126 & $0.02 \%$ & 0.0231 & $0.08 \%$ & -0.0284 & $0.09 \%$ & 0.0290 & $0.10 \%$ & -0.0100 & $0.01 \%$ \\
\hline \multirow{3}{*}{$\begin{array}{l}\text { TC to } \\
\text { HDL-C ratio }\end{array}$} & Model 1 & $0.0663^{*}$ & & $0.0788 *$ & & 0.0553 & & 0.0527 & & 0.0144 & & -0.0085 & \\
\hline & Model 2 & $0.0619^{*}$ & $0.51 \%$ & 0.0393 & $0.17 \%$ & $0.0546^{*}$ & $0.42 \%$ & 0.0128 & $0.02 \%$ & 0.0255 & $0.07 \%$ & 0.0182 & $0.04 \%$ \\
\hline & Model 3 & 0.0632 & $0.55 \%$ & 0.0293 & $0.10 \%$ & $0.0553 *$ & $0.43 \%$ & 0.0045 & $0.00 \%$ & 0.0366 & $0.16 \%$ & 0.0145 & $0.02 \%$ \\
\hline
\end{tabular}

Standardized beta and squared eta are presented. Model 1: unadjusted; Model 2: adjusted for age, BMI, education level, and smoking; Model 3: adjusted for age, BMI, waist circumference, years since menopause (for women), physical activity, education Level, smoking, calcium, phosphorus, and alkaline phosphatase; $a B M D$, areal bone mineral density; $T B S$, trabecular bone score; $T G$, triglyceride; $T C$, total cholesterol; $H D L-C$, high-density lipoprotein cholesterol; $L D L-C$, low-density lipoprotein cholesterol. * $p$ value $<0.05, * * p$ value $<0.001$

and Korean [18] postmenopausal women found no correlations between the serum lipids and the aBMD. Regarding the associations between the TC and LDL-C levels and the aBMD, some studies revealed no associations among the women $[4,21-23,35]$ and the men $[4,24,25]$; however, some showed negative correlations with the femoral aBMD but not with the lumbar spine aBMD [25] in the women. One study reported that only the TC level could be a significant independent risk factor for osteoporosis in postmenopausal women [20]. When considering the association between the HDL-C level and the aBMD, some studies have proposed that the HDL-C level is a risk factor in women $[21,35]$ and in men $[21,24]$. However, some have suggested that it is protective in women $[4,25]$ (just because it has a favorable effect on the cardiovascular risk), but others have reported no association in men [25]. With regard to the correlation between the TG level and the aBMD, some studies have reported positive correlations in women and in men [21,24], while others have found no association in women $[20,35]$. Only a few studies have evaluated the correlations between the aBMD and the LDL-C to HDL-C ratio and the TC to HDL-C ratio. One study showed a negative relationship between the HDL-C to LDL-C ratio and the femoral aBMD but not the lumbar aBMD in both women and men, which persisted in the women after adjusting for adiposity [24].

There are some pathophysiological explanations for the association that has been observed between dyslipidemia and bone loss. Multipotent mesenchymal stem cells in the bone marrow, as progenitor cells, can differentiate into osteoblasts, chondrocytes, and adipocytes, contributing to both bone and fat tissues [36]. It seems that lipid and bone metabolism is correlated and mutually regulated. However, dyslipidemia and lipid metabolism disorders can interact with bone and lead to bone loss. They can also enhance endothelin production, leading to an increase in the risk of thrombus formation. The associations between bone and lipid, from a molecular and biological point of view, are well described in a review article by Tian and Yu [36]. The peroxisome proliferatoractivated receptor $\gamma(\operatorname{PPAR} \gamma)$, which is a mediator of lipid metabolism, is activated by lipid metabolites. PPAR $\gamma$, as well as lipid oxidation products, can inhibit osteoblast differentiation. Moreover, they can direct the progenitor mesenchymal stem cells toward adipogenesis rather than osteogenic differentiation [37, 38]. These mechanisms can enhance bone loss. Additionally, in studies using metabolomic approaches, lipids and fatty acids have been shown to discriminate between osteoporosis and normal conditions, determining the role of lipid metabolism as a related metabolic pathway. For example, one study in China on the association between the metabolome and the aBMD using gas chromatography-mass spectrometry determined the five free fatty acids that had the greatest potential to be used as biomarkers, and the authors suggested that a lipid profile could be useful for the prediction of osteoporotic bone loss [39]. Metabolomic studies performed using the 
Table 4 Association between lipid profile and lumbar spine aBMD

\begin{tabular}{|c|c|c|c|c|c|c|c|}
\hline \multirow[t]{3}{*}{ Lipids } & & \multicolumn{6}{|c|}{ Lumbar spine aBMD tertiles } \\
\hline & & \multicolumn{3}{|c|}{ Women } & \multicolumn{3}{|c|}{ Men } \\
\hline & & $\mathrm{T} 1$ & $\mathrm{~T} 2$ & $\mathrm{~T} 3$ & $\mathrm{~T} 1$ & $\mathrm{~T} 2$ & $\mathrm{~T} 3$ \\
\hline \multirow[t]{3}{*}{ TG } & Model 1 & 1 & $\begin{array}{l}1.0020 \\
(0.9998-1.0042)\end{array}$ & $\begin{array}{l}1.004832 \\
(1.0027-1.0069) * *\end{array}$ & 1 & $\begin{array}{l}1.0038 \\
(1.0016-1.0061)^{*}\end{array}$ & $\begin{array}{l}1.0044 \\
(1.0021-1.0066)^{* * *}\end{array}$ \\
\hline & Model 2 & 1 & $\begin{array}{l}1.0011 \\
(0.9989-1.0033)\end{array}$ & $\begin{array}{c}1.0039 \\
(1.0017-1.0061)^{*}\end{array}$ & 1 & $\begin{array}{l}1.0025 \\
(1.0002-1.0048)^{*}\end{array}$ & $\begin{array}{l}1.0024 \\
(1.0001-1.0048)^{*}\end{array}$ \\
\hline & Model 3 & 1 & $\begin{array}{l}1.0010 \\
(0.9988-1.0033)\end{array}$ & $\begin{array}{c}1.0040 \\
(1.0018-1.0063)^{*}\end{array}$ & 1 & $\begin{array}{l}1.0019 \\
(0.9995-1.0042)\end{array}$ & $\begin{array}{l}1.0018 \\
(0.9995-1.0042)\end{array}$ \\
\hline \multirow[t]{3}{*}{$\mathrm{TC}$} & Model 1 & 1 & $\begin{array}{l}1.0023 \\
(0.9993-1.0053)\end{array}$ & $\begin{array}{c}1.0017 \\
(0.9986-1.0047)\end{array}$ & 1 & $\begin{array}{l}1.0012 \\
(0.9978-1.0047)\end{array}$ & $\begin{array}{l}0.9965 \\
(0.9930-0.9999)^{*}\end{array}$ \\
\hline & Model 2 & 1 & $\begin{array}{l}1.0024 \\
(0.9992-1.0057)\end{array}$ & $\begin{array}{c}1.0021 \\
(0.9987-1.0056)\end{array}$ & 1 & $\begin{array}{l}1.0002 \\
(0.9967-1.0038\end{array}$ & $\begin{array}{l}0.9953 \\
(0.9916-0.9990)^{*}\end{array}$ \\
\hline & Model 3 & 1 & $\begin{array}{l}1.0030 \\
(0.9996-1.0064)\end{array}$ & $\begin{array}{c}1.0024 \\
(0.9988-1.0060)\end{array}$ & 1 & $\begin{array}{l}0.9993 \\
(0.9956-1.0030)\end{array}$ & $\begin{array}{l}0.9941 \\
(0.9903-0.9980)^{*}\end{array}$ \\
\hline \multirow[t]{3}{*}{ HDL-C } & Model 1 & 1 & $\begin{array}{l}0.9911 \\
(0.9794-1.0028)\end{array}$ & $\begin{array}{c}0.9858 \\
(0.9741-0.9977)^{*}\end{array}$ & 1 & $\begin{array}{l}0.9891 \\
(0.9755-1.0028)\end{array}$ & $\begin{array}{l}0.9728 \\
(0.9590-0.9868)^{* * *}\end{array}$ \\
\hline & Model 2 & 1 & $\begin{array}{l}0.9900 \\
(0.9775-1.0027)\end{array}$ & $\begin{array}{c}0.9831 \\
(0.9694-0.9969) *\end{array}$ & 1 & $\begin{array}{l}0.9937 \\
(0.9796-1.0080)\end{array}$ & $\begin{array}{l}0.9795 \\
(0.9648-0.9944)^{*}\end{array}$ \\
\hline & Model 3 & 1 & $\begin{array}{l}0.9896 \\
(0.9765-1.0029)\end{array}$ & $\begin{array}{c}0.9812 \\
(0.9669-0.9958)^{*}\end{array}$ & 1 & $\begin{array}{l}0.9946 \\
(0.9801-1.0092)\end{array}$ & $\begin{array}{l}0.9786 \\
(0.9635-.9940)^{*}\end{array}$ \\
\hline \multirow[t]{3}{*}{ LDL-C } & Model 1 & 1 & $\begin{array}{l}1.0026 \\
(0.9992-1.0061)\end{array}$ & $\begin{array}{c}1.0003 \\
(0.9968-1.0038)\end{array}$ & 1 & $\begin{array}{l}1.0001 \\
(0.9961-1.0042)\end{array}$ & $\begin{array}{l}0.9945 \\
(0.9904-0.9986)^{*}\end{array}$ \\
\hline & Model 2 & 1 & $\begin{array}{l}1.0030 \\
(0.9993-1.0067)\end{array}$ & $\begin{array}{l}1.0014 \\
(0.9974-1.0054)\end{array}$ & 1 & $\begin{array}{l}0.9991 \\
(0.9950-1.0034)\end{array}$ & $\begin{array}{l}0.9937 \\
(0.9894-0.9980)^{*}\end{array}$ \\
\hline & Model 3 & 1 & $\begin{array}{l}1.0036 \\
(0.9998-1.0075)\end{array}$ & $\begin{array}{c}1.0017 \\
(0.9976-1.0058)\end{array}$ & 1 & $\begin{array}{l}0.9982 \\
(0.9939-1.0025)\end{array}$ & $\begin{array}{l}0.9926 \\
(0.9882-0.9971)^{*}\end{array}$ \\
\hline
\end{tabular}

Relative risk ratios with 95\% confidence intervals are presented. Model 1: unadjusted; Model 2: adjusted for age, BMI, education level, and smoking; Model 3: adjusted for age, BMI, waist circumference, years since menopause (for women), physical activity, education level, smoking, calcium, phosphorus, and alkaline phosphatase; $a B M D$, areal bone mineral density; $T G$, triglyceride; $T C$, total cholesterol; $H D L-C$, high-density lipoprotein cholesterol; $L D L-C$, low-density lipoprotein cholesterol. Lumbar aBMD tertile: for men: T1 less than 0.910 , T2 between 0.910 and 1.056 , T3 more than 1.0560; for women T1 less than 0.784 , T2 between 0.784 and 0.865 , T3 more than 0.865 ; $*$ value $<0.05$, ** $p$ value $<0.001$

plasma of ovariectomized rats have revealed increases in the LDL-C, very low-density lipoprotein cholesterol (vLDL-C), and lipid levels [40]. Moreover, we found a positive correlation between the TG level and both the spinal and femoral neck aBMDs in women, but the correlation was lost with the spinal aBMD in the men after adjusting for the age and BMI. This trend in men has been observed in other studies as well [25]. In one UK study, the association between the TG level and the aBMD was no more significant if the body fat percentage was substituted for the waist-hip ratio in the regression model [24]. This can reveal the positive association between the TG level and the aBMD, and if observed, it can be explained by adiposity.

The correlations (either the inverse correlations in men or the lack of correlation in women) observed between the TC and LDL-C levels and the bone status were consistent for the spinal aBMD and the TBS, indicating the similar effects of these lipids on the bone density and quality. The HDL-C was negatively correlated with the spinal and femoral neck aBMDs and the TBS in the men; however, it was negatively correlated with the spinal and femoral neck aBMDs but not the TBS in the women. Moreover, the TG level seemed to have a positive effect on the aBMD but not on the TBS in the women. Therefore, we did not find any positive effects of the TG level on the bone quality. Consistently, the LDL-C to HDL-C ratio and the TC to HDL-C ratio, which are indices of ischemic heart disease [41] and better for determining the cardiovascular risk, were not associated with either the aBMD or the TBS in the men. One study of Turkish postmenopausal women revealed no correlations between the serum lipids and the aBMD, other than weak associations between the $\mathrm{TC}$ and LDL-C levels and the aBMD in the forearm region; however, the results showed the impact of the serum lipids on vertebral fractures [23]. This suggests that the bone quality, rather than the mere density, may be influenced by dyslipidemia, indicating the importance of evaluating the TBS as well as the aBMD. In addition, it has 
Table 5 Association between lipid profile and TBS

\begin{tabular}{|c|c|c|c|c|c|c|c|}
\hline \multirow[t]{3}{*}{ Lipids } & & \multicolumn{6}{|c|}{ TBS tertiles } \\
\hline & & \multicolumn{3}{|c|}{ Women } & \multicolumn{3}{|c|}{ Men } \\
\hline & & $\mathrm{T} 1$ & $\mathrm{~T} 2$ & $\mathrm{~T} 3$ & $\mathrm{~T} 1$ & $\mathrm{~T} 2$ & $\mathrm{~T} 3$ \\
\hline \multirow[t]{3}{*}{ TG } & Model 1 & 1 & $\begin{array}{l}1.0007 \\
(0.9988-1.0026)\end{array}$ & $\begin{array}{l}1.0003 \\
(0.9983-1.0022)\end{array}$ & 1 & $\begin{array}{l}1.0016 \\
(0.9995-1.0036)\end{array}$ & $\begin{array}{l}0.9999 \\
(0.9978-1.0020)\end{array}$ \\
\hline & Model 2 & 1 & $\begin{array}{l}1.0013 \\
(0.99933-1.0034)\end{array}$ & $\begin{array}{l}1.0008 \\
(0.9988-1.0030)\end{array}$ & 1 & $\begin{array}{l}1.0030 \\
(1.0008-1.0052)^{*}\end{array}$ & $\begin{array}{l}1.0003 \\
(0.9980-1.0026)\end{array}$ \\
\hline & Model 3 & 1 & $\begin{array}{l}1.0016 \\
(0.9995-1.0037)\end{array}$ & $\begin{array}{l}1.0017 \\
(0.9995-1.0039)\end{array}$ & 1 & $\begin{array}{l}1.0031 \\
(1.0008-1.0053)^{*}\end{array}$ & $\begin{array}{l}1.0006 \\
(0.9982-1.0029)\end{array}$ \\
\hline \multirow[t]{3}{*}{$\mathrm{TC}$} & Model 1 & 1 & $\begin{array}{l}1.0014 \\
(0.9984-1.0044)\end{array}$ & $\begin{array}{l}1.0007 \\
(0.9976-1.0037)\end{array}$ & 1 & $\begin{array}{l}0.9994 \\
(0.9960-1.0029)\end{array}$ & $\begin{array}{l}0.9958 \\
(0.9923-0.9992) *\end{array}$ \\
\hline & Model 2 & 1 & $\begin{array}{l}1.0017 \\
(0.9986-1.0048)\end{array}$ & $\begin{array}{l}1.0013 \\
(0.9981-1.0045)\end{array}$ & 1 & $\begin{array}{l}0.9997 \\
(0.9961-1.0032)\end{array}$ & $\begin{array}{l}0.9955 \\
(0.9919-0.9992) *\end{array}$ \\
\hline & Model 3 & 1 & $\begin{array}{l}1.0015 \\
(0.9983-1.0047)\end{array}$ & $\begin{array}{l}1.0007 \\
(0.9974-1.0040)\end{array}$ & 1 & $\begin{array}{l}0.9991 \\
(0.9955-1.0027)\end{array}$ & $\begin{array}{l}0.9950 \\
(0.9913-0.9988)^{*}\end{array}$ \\
\hline \multirow[t]{3}{*}{ HDL-C } & Model 1 & 1 & $\begin{array}{l}0.9954 \\
(0.9836-1.0073)\end{array}$ & $\begin{array}{l}0.9993 \\
(0.9875-1.0112)\end{array}$ & 1 & $\begin{array}{l}0.9939 \\
(0.9801-1.0079)\end{array}$ & $\begin{array}{l}0.9935 \\
(0.9798-1.0074)\end{array}$ \\
\hline & Model 2 & 1 & $\begin{array}{l}0.9941 \\
(0.9818-1.0067)\end{array}$ & $\begin{array}{l}0.9967 \\
(0.9840-1.0095)\end{array}$ & 1 & $\begin{array}{l}0.9858 \\
(0.9716-1.0002)\end{array}$ & $\begin{array}{l}0.9885 \\
(0.9740-1.0033)\end{array}$ \\
\hline & Model 3 & 1 & $\begin{array}{l}0.9908 \\
(0.9778-1.0040)\end{array}$ & $\begin{array}{l}0.9882 \\
(0.9749-1.0018)\end{array}$ & 1 & $\begin{array}{l}0.9854 \\
(0.9710-1.0000)\end{array}$ & $\begin{array}{l}0.9882 \\
(0.9733-1.0032)\end{array}$ \\
\hline \multirow[t]{3}{*}{ LDL-C } & Model 1 & 1 & $\begin{array}{l}1.0017 \\
(0.9983-1.0052)\end{array}$ & $\begin{array}{l}1.0006 \\
(0.9971-1.0041)\end{array}$ & 1 & $\begin{array}{l}0.9985 \\
(0.9945-1.0026)\end{array}$ & $\begin{array}{l}0.9948 \\
(0.9908-0.9989) *\end{array}$ \\
\hline & Model 2 & 1 & $\begin{array}{l}1.0019 \\
(0.9983-1.0054)\end{array}$ & $\begin{array}{l}1.0013 \\
(0.9976-1.0049)\end{array}$ & 1 & $\begin{array}{l}0.9985 \\
(0.9944-1.0027)\end{array}$ & $\begin{array}{l}0.9946 \\
(0.9904-0.9989) *\end{array}$ \\
\hline & Model 3 & 1 & $\begin{array}{l}1.0016 \\
(0.9980-1.0052)\end{array}$ & $\begin{array}{l}1.0006 \\
(0.9969-1.0044)\end{array}$ & 1 & $\begin{array}{l}0.9978 \\
(0.9936-1.0021)\end{array}$ & $\begin{array}{l}0.9939 \\
(0.9895-0.9982) *\end{array}$ \\
\hline
\end{tabular}

Relative risk ratios with 95\% confidence intervals are presented. Model 1: unadjusted; Model 2: adjusted for age, BMI, education level, and smoking; Model 3: adjusted for age, BMI, waist circumference, years since menopause (for women), physical activity, education level, smoking, calcium, phosphorus, and alkaline phosphatase; $T B S$, trabecular bone score; $T G$, triglyceride; $T C$, total cholesterol; $H D L-C$, high-density lipoprotein cholesterol; $L D L-C$, low-density lipoprotein cholesterol. TBS tertiles: for men: T1 less than 1.324, T2 between 1.324 and 1.395, T3 more than 1.395; for women T1 less than 1.205 , T2 between 1.205 and 1.280 and T3 more than $1.280 ; * p$ value $<0.05$, $* * p$ value $<0.001$

been suggested that obesity has opposing effects on the bone health, and a higher BMI may be associated with a higher aBMD, while it may also be associated with poor metabolic health and bone strength. This effect on bone health has been shown to vary among different age and gender categories [42]. Therefore, obese patients and underweight patients could be at risk for fragility fractures, both requiring attention. Another study revealed that weight loss is associated with decreased lumbar spine and total hip aBMDs but an increased TBS when assessed via densitometry [29]. Thus, the factors predicting TBS changes may differ from those predicting aBMD changes. However, the longitudinal findings in elderly men who were losing weight have suggested that the association between the fat mass and bone mass is not limited to its loading effect, that fat and bone also have a metabolic relationship, and that the role of fat in bone metabolism increases with age [43]. In order to have healthy bones, it is important for elderly men to maintain their body weight and fat mass, and this highlights the importance of the prevention of osteosarcopenia in the elderly.

This study did have a number of limitations. For example, we did not have access to the supplement intakes, vitamin D levels, or fracture data of the participants. However, the main strength of this study lies in the fact that we included men as well as women through a large sample size population-based study. Additionally, for the first time, as far as we know, we evaluated the correlations between the lipid profile and the TBS as a novel index of bone quality. We also included the LDL-C to HDL-C ratio and the TC to HDL-C ratio as indices of the cardiovascular risk in our analyses. However, no causal relationship can be concluded due to the study's crosssectional design. Moreover, the participants may not be representative of the entire Iranian population. We adjusted the analysis for the age, BMI, waist circumference, years since menopause (for the women), physical activity, educational level, and smoking status because these are the major factors affecting the bone. 


\section{Conclusion}

This study showed that the elderly men with higher TC, HDL$\mathrm{C}$, and LDL-C levels had lower lumbar spine aBMDs and worse TBSs. However, the elderly women with higher HDL-C (but not TC and LDL-C) levels exhibited lower femoral neck and lumbar spine aBMDs but not TBSs. Moreover, the elderly women with higher TG levels had higher lumbar spine and femoral neck aBMDs, while the elderly men with higher TG levels had higher femoral neck aBMDs. This emphasizes the need for simultaneous preventive actions for cardiovascular disease and osteoporosis. However, the underlying mechanisms may differ between men and women; therefore, this requires investigation.

\section{Compliance with ethical standards}

\section{Conflict of interest None.}

Statement of human rights All of the procedures performed in this study involving human participants were in accordance with the ethical standards of the institutional and/or national research committee and with the 1964 Helsinki declaration and its later amendments or comparable ethical standards. Informed and written consent was obtained from all of the individual participants included in this study.

\section{References}

1. Garg A, Kay S (2018) Osteoporosis: a disease of men. Health 10(01):69-74

2. Fischer S, Kapinos KA, Mulcahy A, Pinto L, Hayden O, Barron R (2017) Estimating the long-term functional burden of osteoporosisrelated fractures. Osteoporos Int 28(10):2843-2851

3. Irani AD, Poorolajal J, Khalilian A, Esmailnasab N, Cheraghi Z (2013) Prevalence of osteoporosis in Iran: a meta-analysis. J Res Med Sci: Off J Isfahan Univ Med Sci 18(9):759-766

4. Lian XL, Zhang YP, Li X, Jing LD, Cairang ZM, Gou JQ (2017) Exploration on the relationship between the elderly osteoporosis and cardiovascular disease risk factors. Eur Rev Med Pharmacol Sci 21(19):4386-4390

5. Rosso AL, Wisdom JP, Horner-Johnson W, McGee MG, Michael YL (2011) Aging with a disability: a systematic review of cardiovascular disease and osteoporosis among women aging with a physical disability. Maturitas 68(1):65-72

6. den Uyl D, Nurmohamed MT, van Tuyl LH, Raterman HG, Lems WF (2011) (Sub)clinical cardiovascular disease is associated with increased bone loss and fracture risk; a systematic review of the association between cardiovascular disease and osteoporosis. Arthritis Res Ther 13(1):R5

7. Laroche M, Pecourneau V, Blain H, Breuil V, Chapurlat R, Cortet B, Sutter B, Degboe Y, committee Gs (2017) Osteoporosis and ischemic cardiovascular disease. Joint, Bone, Spine : Revue du Rhumatisme 84(4):427-432

8. Lello S, Capozzi A, Scambia G (2015) Osteoporosis and cardiovascular disease: an update. Gynecol Endocrinol : Off J Int Soc Gynecol Endocrinol 31(8):590-594

9. Register TC, Hruska KA, Divers J, Bowden DW, Palmer ND, Carr JJ, Wagenknecht LE, Hightower RC, Xu J, Smith SC (2014) Sclerostin is positively associated with bone mineral density in men and women and negatively associated with carotid calcified atherosclerotic plaque in men from the African American-Diabetes Heart Study. J Clin Endocrinol Metab 99(1):315-321

10. Hofbauer LC, Schoppet M (2004) Clinical implications of the osteoprotegerin/RANKL/RANK system for bone and vascular diseases. Jama 292(4):490-495

11. Brandenburg VM, Kleber ME, Vervloet MG, Tomaschitz A, Pilz S, Stojakovic T, Delgado G, Grammer TB, Marx N, März W (2014) Fibroblast growth factor 23 (FGF23) and mortality: the Ludwigshafen risk and cardiovascular health Study. Atherosclerosis 237(1):53-59

12. Mirza MA, Karlsson MK, Mellström D, Orwoll E, Ohlsson C, Ljunggren Ö, Larsson TE (2011) Serum fibroblast growth factor23 (FGF-23) and fracture risk in elderly men. J Bone Miner Res 26(4):857-864

13. Fernández-Murga ML, Vinué Á, Caeiro JR, Guede D, Tarín JJ, Andrés V, Cano A (2015) Impact of estrogens on atherosclerosis and bone in the apolipoprotein E-deficient mouse model. Menopause 22(4):428-436

14. McLean RR (2009) Proinflammatory cytokines and osteoporosis. Curr Osteoporos Rep 7(4):134-139

15. Igase M, Kohara K, Tabara Y, Ohara M, Takita R, Ochi M, Okada Y, Miki T (2014) Change in arterial stiffness associated with monthly bisphosphonate treatment in women with postmenopausal osteoporosis. Menopause 21(9):962-966

16. An T, Hao J, Sun S, Li R, Yang M, Cheng G, Zou M (2017) Efficacy of statins for osteoporosis: a systematic review and metaanalysis. Osteoporos Int 28(1):47-57

17. Hernández JL, Olmos JM, Romaña G, Martinez J, Castillo J, Yezerska I, Pinedo G, González-Macías J (2014) Bone mineral density in statin users: a population-based analysis from a Spanish cohort. J Bone Miner Metab 32(2):184-191

18. Go JH, Song YM, Park JH, Park JY, Choi YH (2012) Association between serum cholesterol level and bone mineral density at lumbar spine and femur neck in postmenopausal Korean women. Korean J Fam Med 33(3):166-173

19. Ghadiri-Anari A, Mortezaii-Shoroki Z, Modarresi M, Dehghan A (2016) Association of lipid profile with bone mineral density in postmenopausal women in Yazd province. Int J Reprod Biomed 14(9):597-602

20. Bijelic R, Balaban J, Milicevic S (2016) Correlation of the lipid profile, BMI and bone mineral density in postmenopausal women. Materia socio-medica 28(6):412-415. https://doi.org/10.5455/ msm.2016.28.412-415

21. Cui R, Zhou L, Li Z, Li Q, Qi Z, Zhang J (2016) Assessment risk of osteoporosis in Chinese people: relationship among body mass index, serum lipid profiles, blood glucose, and bone mineral density. Clin Interv Aging 11:887-895

22. Pliatsika P, Antoniou A, Alexandrou A, Panoulis C, Kouskouni E, Augoulea A, Dendrinos S, Aravantinos L, Creatsa M, Lambrinoudaki I (2012) Serum lipid levels and bone mineral density in Greek postmenopausal women. Gynecol Endocrinol :Off J Int Soc Gynecol Endocrinol 28(8):655-660

23. Sivas F, Alemdaroglu E, Elverici E, Kulug T, Ozoran K (2009) Serum lipid profile: its relationship with osteoporotic vertebrae fractures and bone mineral density in Turkish postmenopausal women. Rheumatol Int 29(8):885-890

24. Dennison EM, Syddall HE, Aihie Sayer A, Martin HJ, Cooper C, Hertfordshire Cohort Study G (2007) Lipid profile, obesity and bone mineral density: the Hertfordshire Cohort Study. QJM : Monthly J Assoc Phys 100(5):297-303

25. Garg MK, Marwaha RK, Tandon N, Bhadra K, Mahalle N (2014) Relationship of lipid parameters with bone mineral density in Indian population. Indian J Endocrinol Metab 18(3):325-332

26. Silva BC, Broy SB, Boutroy S, Schousboe JT, Shepherd JA, Leslie WD (2015) Fracture risk prediction by non-BMD DXA measures: 
the 2015 ISCD official positions part 2: trabecular bone score. J Clin Densitom 18(3):309-330

27. McNamara EA, Kilim HP, Malabanan AO, Whittaker LG, Rosen HN (2018) Enhanced precision of the new Hologic horizon model compared with the old discovery model is less evident when fewer vertebrae are included in the analysis. J Clin Densitom 21(1):125-129

28. Alam S, Ueki K, Nakagawa K, Marukawa K, Hashiba Y, Yamamoto E, Sakulsak N, Iseki S (2009) Statin-induced bone morphogenetic protein (BMP) 2 expression during bone regeneration: an immunohistochemical study. Oral Surg Oral Med Oral Pathol Oral Radiol Endod 107(1):22-29

29. Ishihara Y, Ueki K, Sotobori M, Marukawa K, Moroi A (2014) Bone regeneration by statin and low-intensity pulsed ultrasound (LIPUS) in rabbit nasal bone. J Craniomaxillofac Surg: Off Publ Eur Assoc Craniomaxillofac Surg 42(3):185-193

30. Shafiee G, Ostovar A, Heshmat R, Darabi H, Sharifi F, Raeisi A, Mehrdad N, Shadman Z, Razi F, Amini MR, Arzaghi SM, Meybodi HA, Soltani A, Nabipour I, Larijani B (2017) Bushehr Elderly Health (BEH) programme: study protocol and design of musculoskeletal system and cognitive function (stage II). BMJ Open 7(8): e013606

31. Ostovar A, Nabipour I, Larijani B, Heshmat R, Darabi H, Vahdat K, Ravanipour M, Mehrdad N, Raeisi A, Heidari G (2015) Bushehr Elderly Health (BEH) Programme, phase I (cardiovascular system). BMJ Open 5(12):e009597

32. Shepherd JA, Schousboe JT, Broy SB, Engelke K, Leslie WD (2015) Executive summary of the 2015 ISCD position development conference on advanced measures from DXA and QCT: fracture prediction beyond BMD. J Clin Densitom 18(3):274-286

33. Bousson V, Bergot C, Sutter B, Levitz P, Cortet B (2012) Trabecular bone score (TBS): available knowledge, clinical relevance, and future prospects. Osteoporos Int 23(5):1489-1501

34. Shevroja E, Lamy O, Kohlmeier L, Koromani F, Rivadeneira F, Hans D (2017) Use of trabecular bone score (TBS) as a complementary approach to dual-energy X-ray absorptiometry (DXA) for fracture risk assessment in clinical practice. J Clin Densitom 20(3): 334-345

35. Li S, Guo H, Liu Y, Wu F, Zhang H, Zhang Z, Xie Z, Sheng Z, Liao E (2015) Relationships of serum lipid profiles and bone mineral density in postmenopausal Chinese women. Clin Endocrinol 82(1):53-58

36. Tian L, Yu X (2015) Lipid metabolism disorders and bone dysfunction-interrelated and mutually regulated (review). Mol Med Rep 12(1):783-794. https://doi.org/10.3892/mmr.2015.3472

37. Nuttall ME, Gimble JM (2004) Controlling the balance between osteoblastogenesis and adipogenesis and the consequent therapeutic implications. Curr Opin Pharmacol 4(3):290-294

38. Yamaguchi T, Sugimoto T, Yano S, Yamauchi M, Sowa H, Chen Q, Chihara K (2002) Plasma lipids and osteoporosis in postmenopausal women. Endocr J 49(2):211-217

39. Qi H, Bao J, An G, Ouyang G, Zhang P, Wang C, Ying H, Ouyang P, Ma B, Zhang Q (2016) Association between the metabolome and bone mineral density in pre-and post-menopausal Chinese women using GC-MS. Mol BioSyst 12(7):2265-2275

40. Xue L, Wang Y, Liu L, Zhao L, Han T, Zhang Q, Qin L (2011) A 1HNMR-based metabonomics study of postmenopausal osteoporosis and intervention effects of er-xian decoction in ovariectomized rats. Int J Mol Sci 12(11):7635-7651

41. Lemieux I, Lamarche B, Couillard C, Pascot A, Cantin B, Bergeron J, Dagenais GR, Després J-P (2001) Total cholesterol/HDL cholesterol ratio vs LDL cholesterol/HDL cholesterol ratio as indices of ischemic heart disease risk in men: the Quebec Cardiovascular Study. Arch Intern Med 161(22):2685-2692

42. Gower BA, Casazza K (2013) Divergent effects of obesity on bone health. J Clin Densitom 16(4):450-454

43. Bleicher K, Cumming RG, Naganathan V, Travison TG, Sambrook PN, Blyth FM, Handelsman DJ, Le Couteur DG, Waite LM, Creasey HM (2011) The role of fat and lean mass in bone loss in older men: findings from the CHAMP study. Bone 49(6):12991305

Publisher's note Springer Nature remains neutral with regard to jurisdictional claims in published maps and institutional affiliations. 